\title{
Epidermal ve dermal benin deri lezyonlarında ablatif fraksiyonel Er: Yag (Erbium: Yttrium-Aluminum-Garnet) lazer tedavisinin etkinliği: Retrospektif çalıșma
}

\author{
Efficiency of ablative fractional Er: YAG (Erbium: Yttrium-Aluminum-Garnet) laser in \\ the treatment of benign epidermal and dermal skin lesions: A retrospective study
}

Erol Koç, Yıldıray Yeniay, Hakan Yeșil, Ercan Çalıșkan, Gürol Açıkgöz Gülhane Askeri Tıp Akademisi, Dermatoloji Anabilim Dalı, Ankara, Türkiye

\begin{abstract}
Özet
Amaç: Epidermal ve dermal benin deri lezyonlarının tedavisinde en ideal ablazyon yöntemlerinden biri Er: YAG lazer sistemleridir. Bu çalışmada epidermal ve dermal benin deri lezyonlarında Er: YAG lazer tedavisinin etkinliğini retrospektif olarak araştırdık.

Yöntem ve Gereçler: Kliniğimizde Nisan 2011-Nisan 2013 dönemleri arasında epidermal ve dermal benin deri lezyonları nedeniyle Er: YAG lazer tedavisi uyguladığımı 116 hastanın kayıtları retrospektif olarak incelendi. Bu değerlendirmede 103 hastanın (47 erkek, 56 kadın) verileri çalışma için uygun görüldü. Çalışmaya alınan 103 hastanın lezyonları ksantelezma, solar lentigo, epidermal nevüs, seboreik keratoz, ota nevüs, siringoma, cafe au lait makülleri (CALM) ve diğer lezyonlar şeklindeydi. Hastaların dosyalarından tedavi parametreleri, demografik özellikleri, tedavi öncesi ve sonrası fotoğrafları incelenerek Er: YAG lazer tedavisinin etkinliği değerlendirildi.

Bulgular: Çalışmaya dahil edilen 103 hastada lezyonlar; ksantelezma ( $n=21)$, siringoma $(n=17)$, solar lentigo ( $n=16)$, epidermal nevüs ( $n=11$ ), seboreik keratoz $(n=9)$, ota nevüs $(n=5), C A L M(n=3)$ ve diğer lezyonlar $(n=21)$ olmak üzere 8 grup altında değerlendirildi. Er: YAG lazer tedavisi uygulanan ortalama enerji akımı 3-7 J/cm2, ortalama atım süresi $300 \mathrm{~ms}$, ortalama geçiş sayısı 3-5 tekrar ve ortalama atım frekansı 3-7 Hz idi. Hastaların \%59,2'sinde belirgin düzelme, $\% 26,2$ 'sinde orta derecede düzelme ve $\% 9,7$ 'sinde hafif düzelme saptanırken, $\% 4,9$ 'unda düzelme saptanmadı. Tedavi yanıtları ksantelezma, solar lentigo, epidermal nevüs, siringoma ve CALM hastalarında istatistiksel olarak anlamlı bulundu. Gözlenen yan etkiler ise, 4 hastada hiperpigmentasyon, 3 hastada hipopigmentasyon, 2 hastada hipertrofik skar ve 1 hastada kalıcı eritem olup, tedavi tüm hastalar tarafından iyi tolere edildi.

Sonuç: Er: YAG lazer, özellikle epidermal yerleşimin ön planda olduğu benin deri lezyonlarının tedavisinde etkili ve güvenilir bir tedavi seçeneğidir. (Türkderm 2014; 48: 31-8)

Anahtar Kelimeler: Epidermal-dermal lezyonlar, Lazer, Er: YAG lazer, tedavi

\section{Summary}

Background and Design: Er: YAG lasers are precise ablation systems used in the treatment benign epidermal and dermal skin lesions. In this study, we retrospectively analysed the efficiency of Er: YAG laser therapy in the treatment of benign epidermal and dermal skin lesions. Materials and Methods: We retrospectively investigated the medical records of 116 patients treated with Er: YAG laser in our clinic between April 2011 and April 2013. The clinical data of 103 patients (47 men, 56 women) with xanthelasma, solar lentigo, epidermal nevus, seborrheic keratosis, nevus of ota, syringoma, cafe au lait macules (CALM) or other than these were included in the study. Treatment parameters, demographic features of the patients, and before and after photos of the lesions were investigated from patients' records in order to evaluate the efficiency of Er: YAG laser therapy.
\end{abstract}

Yazışma Adresi/Address for Correspondence: Dr. Erol Koç, Gülhane Askeri Tıp Akademisi, Tip Fakültesi, Dermatoloji Anabilim Dalı, Ankara, Türkiye Tel.: +90 3123044468 E-posta: ekoc@gata.edu.tr Geliş Tarihi/Received: 20.05.2013 Kabul Tarihi/Accepted: 11.06.2013 
Results: The patients included in the study were evaluated in 8 groups: xanthelasma $(n=21)$, syringoma $(n=17)$, solar lentigo ( $n=16)$, epidermal nevus ( $n=11)$, seborrheic keratosis $(n=9)$, nevus of ota $(n=5), \operatorname{CALM~}(n=3)$ and other than these $(n=21)$. In the Er: YAG laser treatment, the average energy flow was 3-7 J/cm², the average pulse duration was $300 \mathrm{~ms}$, the average number of passes was 3-5 repeats, and the average pulse frequency was 3-7 Hz. While no improvement was observed in $4.9 \%$ of patients, $59.2 \%$ of subjects showed marked improvement, $26.2 \%$ showed moderate and $9.7 \%$ of patients showed mild improvement. Treatment responses in xanthelasma, syringoma, epidermal nevus, solar lentigo and CALM lesions were statistically significant. The observed side effects were hyperpigmentation in 4 patients, hypopigmentation in 3 patients, hypertrophic scar in 2 patients and persistent erythema in one patient. The treatment was well tolerated by all the subjects.

Conclusion: Er: YAG laser is an effective and safe treatment option in the treatment of benign skin lesions especially in epidermal lesions. (Turkderm 2014; 48: 31-8) Key Words: Epidermal-dermal lesions, laser, Er: YAG laser, treatment

\section{Giriş}

Epidermal ve dermal benin deri lezyonlarının tedavisinde en ideal ablazyon yöntemi, epidermisin hassas bir şekilde ortadan kaldırılması ve dermiste minimal hasar oluşturulmasıdır. Bu yöntem ile skar riski olmadan benin deri lezyonlarının tedavisi mümkün olmaktadır. Dermatolojide lazer sistemleri kullanılmadan önce benin deri lezyonlarının tedavisinde uygulanan tüm tıbbi ve cerrahi işlemler, hassas bir ablazyon yetisinden yoksun olduklarından ciddi bir skar riski oluşturmaktaydı. Lazer sistemlerindeki gelişmelerle birlikte ablazyon için selektif fototermoliz kullanan ve su molekülünü kromofor olarak seçen kısa atım süresine sahip Er: YAG (Erbium: Yttrium-AluminumGarnet) lazer sistemleri geliştirilmiştir. Er: YAG lazer; su moleküllerinin absorbsiyon pikine yakın 2940 nm dalga boyuna sahip olup, yüksek enerjiyi kısa sürede dokuya vermekte ve çevre dokuda termal hasar oluşmaksızın hassas bir ablazyona neden olmaktadır ${ }^{1}$. Her J/ $\mathrm{cm}^{2}$ lik enerji akımında 2-4 $\mathrm{mm}$ derine penetre olurlar ve benin deri lezyonlarının tedavisinde ideal bir ablazyon oluştururlar².

Bu çalışmada epidermal ve dermal benin deri lezyonları nedeniyle Er: YAG lazer tedavisi uygulanan hastalar retrospektif olarak değerlendirilmiştir. Çalışmamızın amacı, Er: YAG lazerin epidermal ve dermal benin deri lezyonlarındaki etkinliğini, yan etki ve tolerabilitesini değerlendirmektir.

\section{Gereç ve Yöntem}

\section{Lazer sistemi}

Kliniğimizde değişken kare atım teknolojisi ile atım süresi ve enerjisi ayarlanabilen Er: YAG lazer sistemi (XS Dynamis, Fotona, Ljubljana, Slovenia) kullanılmaktadır. Cihaz, 2940 nm dalga boyunda olup, VSP (Very Short Pulse) modunda 100 ms, SP (Short Pulse) modunda 300 ms, LP (Long Pulse) modunda 600 ms ve XLP (Ekstra Long Pulse) modunda $1500 \mathrm{~ms}$ atım süresine sahiptir. Lazer sisteminin gösterebildiği en yüksek enerji akımı $95 \mathrm{~J} / \mathrm{cm}^{2}$ dir. Spot büyüklüğü el ünitesinde ayarlanmakta olup, 2-7 mm arasında değişmektedir.

\section{Hasta profili}

Çalışmamızda kliniğimizde Nisan 2011-Nisan 2013 dönemleri arasında epidermal ve dermal benin deri lezyonları nedeniyle Er: YAG lazer tedavisi uygulanan toplam 116 hastanın kayıtları retrospektif olarak değerlendirildi. Hasta dosyalarından hastaların demografik özellikleri, tedavi öncesi ve sonrası fotoğrafları, tedavi parametreleri ve hastalara uygulanan anketin sonuçları incelendi. Bu değerlendirmede 103 hastanın (47 erkek, 56 kadın) verileri çalışma için uygun görüldü. Geri kalan hasta grubunda, 6 hasta; fotoğraflarının olmaması, 5 hasta; dosya bilgilerinin eksik olması, 2 hasta; kontrol muayenelerine gelmemesi nedeniyle çalışma dışı bırakıldı. Değerlendirmeye alınan 103 hastanın lezyonları ksantelezma, solar lentigo, epidermal nevüs, seboreik keratoz, ota nevüs, siringoma, cafe au lait makülleri (CALM) ve diğer lezyonlar şeklinde sınıflandırıldı. Kliniğimizde lazer tedavisi planlanan tüm hastalar işlem konusunda bilgilendirilmiş ve aydınlatılmış onam formundaki bilgiler ışığında onayları alınmıştı. Çalışma için yerel etik kurul onayı alınmıştır (06 Haziran 2012-04).

Lazer tedavisi öncesinde ve sırasında hastanın değerlendirilmesi Yüzeyel ablazyon yapılan olgularda ciddi bir anestezi ihtiyacı olmamasına karşın derin ablazyon gereken olgularda işlemden 30 dakika önce \%2,5 lidokain ve \%2,5 prilokain içeren krem topikal olarak uygulandı. Anestezi sağlandıktan sonra tüm lezyon yüzeyine ve dermarkasyon hattı oluşmaması için periferindeki sağlam deriye Er: YAG lazer ile lezyonun tipine ve yapısına göre çoklu geçişler uygulandı. Tüm lezyonlar tipine, yapısına ve yaygınlığına göre değerlendirildi. Lazer parametreleri (akım şiddeti, atım tipi, frekansı ve spot büyüklüğü) üretici firmanın önerileri ve kişisel deneyimler göz önüne alınarak dikkatli bir şekilde ayarlandı. Göz çevresi gibi hassas bölgelerde ve küçük lezyonlarda (siringoma, ksantelezma gibi) 2-3 mm spot büyüklüğü tercih edildi. Geniş lezyonlarda ise (Ota nevüs, epidermal nevüs gibi) 5-7 mm spot büyüklüğü tercih edildi. Hastalarda hassas bir ablazyon sağlamak için cihazın SP modu seçildi. Akım şiddeti ve atım süresi lazer işlemi sırasında oluşan ablazyon derinliğine bakılarak kademeli olarak arttırıldı.

\section{Lazer tedavisi sonrasında hastanın değerlendirilmesi}

Er: YAG lazer ile ablazyon tedavisi alan tüm hastalara standart yara bakımı uygulandı. Önce ölü dokular serum fizyolojik ve gazlı bez yardımıyla silinerek uzaklaştıııldı. Sonrasında lezyon yara örtüsü (Bactigras ${ }^{\mathrm{TM}}$, Smith\&Nephew, London, UK), transparan film (Tegaderm ${ }^{\mathrm{TM}}$, 3M, St. Paul, MT, USA) ya da adeziv yara örtüsü (Steri-Strip ${ }^{\mathrm{TM}}, 3 \mathrm{M}$, St. Paul, MT, USA) ile kapatıldı. Tedavi alanında reepitelizasyon izlenene kadar günlük pansumana devam edildi ve gerek görülen olgularda 3-4 hafta sonra ek tedavi seansları planlandı. Klinik değerlendirmenin objektif bir şekilde yapılabilmesi için tedavi öncesi ve sonrası hastaların fotoğrafları çekildi ve dosyalarına konuldu.

Hastalar, lazer konusunda uzman bir dermatolog tarafından dosyalarında bulunan tedavi öncesi ve sonrası fotoğrafları karşılaştırılarak değerlendirildi. Gerek görülen olgularda hastaya ulaşılarak kontrol muayenesine tekrar gelmeleri istendi. Elde edilen klinik yanıt lezyondaki düzelme oranına göre derecelendirildi (\%0-25=düzelme yok, \%26-50=hafif düzelme, \%51-75=orta derecede düzelme, \%76-100=belirgin düzelme). Ayrıca hastaların kontrol vizitlerinde doldurdukları değerlendirme anketleri dosyalarından çıkartıldı ve tedavi memnuniyetleri değerlendirmeye alındı (-1=kötü, $0=$ değişiklik yok, $1=$ orta, 2=iyi, 3=çok iyi).

\section{İstatistiksel analiz}

Çalışmamı elde edilen tedavi yanıtları ve hasta memnuniyetleri tanımlayıcı araştırma olarak değerlendirildi ve sonuçlar yüzdeler şeklinde belirtildi. Lezyon tipine göre tedavi yanıtları karşılaştıııırken Wilcoxon 
testi kullanıldı. Tüm verilerin istatistiksel analizleri için SPSS version 10.0 (SPSS Inc., Chigaco, IL, USA) programı kullanıldı. İstatistiksel değerlendirmede $p<0,05$ değeri istatistiksel olarak anlamlı kabul edildi.

\section{Bulgular}

Çalışmamızda 2011-2013 yılları arasında epidermal ve dermal benin deri lezyonlarının tedavisi için Er: YAG lazer tedavisi alan toplam 116 hastanın dosyasına ulaşıldı. Dosya incelemesi sırasında 103 hastanın (47 erkek, 56 kadın) verileri çalışma için uygun görüldü. Hastaların yaş ortalaması 35,6 (yaş aralığı 15-74 yıl) idi. Er: YAG lazer ile uygulanan ortalama enerji akımı 3-7 J/ $\mathrm{cm}^{2}$, ortalama atım süresi 300 ms, ortalama geçiş sayısı 3-5 tekrar ve ortalama atım frekansı 3-7 Hz'dir. Çalışmaya dahil edilen 103 hasta lezyon tiplerine göre; ksantelezma $(n=21)$, siringoma $(n=17)$, solar lentigo $(n=16)$, epidermal nevüs $(n=11)$, seboreik keratoz $(n=9)$, ota nevüs $(n=5), \operatorname{CALM~}(n=3)$ ve diğer lezyonlar $(n=21)$ olmak üzere 8 gruba ayrıldı. Hastaların demografik özellikleri, lezyon tipleri ve tedavi parametreleri Tablo 1'de özetlenmiştir.

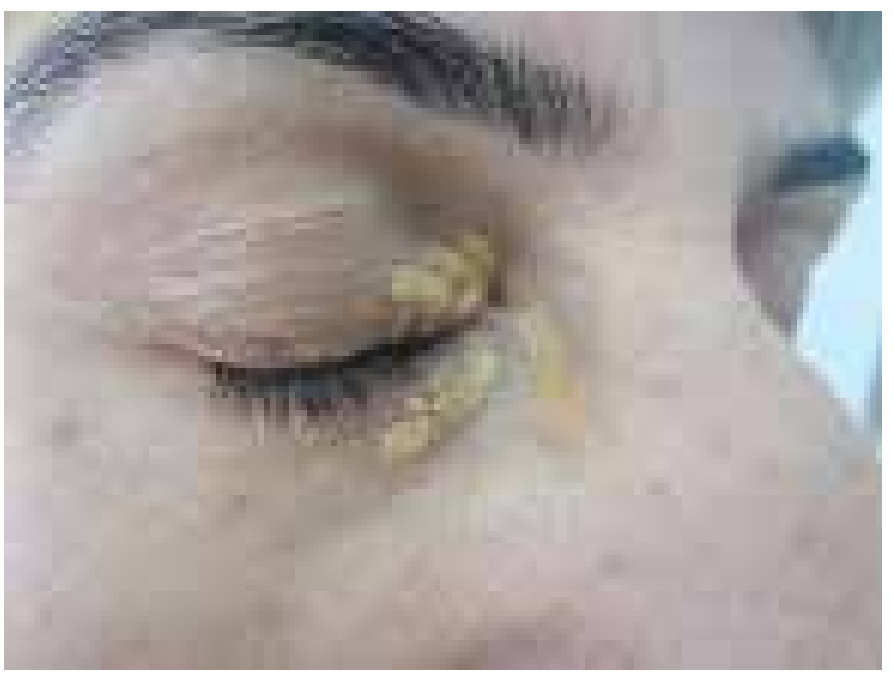

Ksantelezma nedeniyle toplam 21 hasta (5 erkek, 16 kadın) Er: YAG lazer ile tedavi edildi. Hastaların yaş ortalaması 38,5 (yaş aralığı 21-51 yıl) idi. Ksantelezma, yüzeyel yerleşim göstermesinden dolayı ortalama 1-2 seans lazer uygulaması tedavi için yeterli olmuştur (akım şiddeti: 5-7 J/cm², frekansı: 5-6 Hz, spot büyüklüğü: 3-5 mm, akım tipi: SP). Hastaların tamamı tedaviye iyi yanıt vermiş olup, sonuç istatistiksel olarak anlamlı bulunmuştur $(p<0,05)$. Ksantelezmalı bir olgumuza ait tedavi öncesi ve sonrası fotoğrafları Resim $1 \mathrm{~A}$ ve $1 \mathrm{~B}^{\prime}$ de gösterilmektedir. Siringoma nedeniyle toplam 17 hasta (11 erkek, 6 kadın) Er: YAG lazer ile tedavi edildi. Hastaların yaş ortalaması 26,2 (yaş aralığı 2131 yıl) idi. Siringoma lezyonlarının tedavisi için ortalama 2-3 seans lazer uygulamasına yeterli olmuştur (akım şiddeti: $5-7 \mathrm{~J} / \mathrm{cm}^{2}$, frekansı: 5-6 Hz, spot büyüklüğü: 3-5 mm, akım tipi: SP). Hastaların \%94,1'i tedaviye iyi yanıt vermiş olup, sonuç istatistiksel olarak anlamlı bulunmuştur $(p<0,05)$. Siringomalı bir olgumuza ait tedavi öncesi ve sonrası fotoğrafları Resim 2A ve 2B'de gösterilmektedir.

Solar lentigo nedeniyle toplam 16 hasta (5 erkek, 11 kadın) Er: YAG lazer ile tedavi edildi. Hastaların yaş ortalaması 42,5 (yaş aralığı 21-74

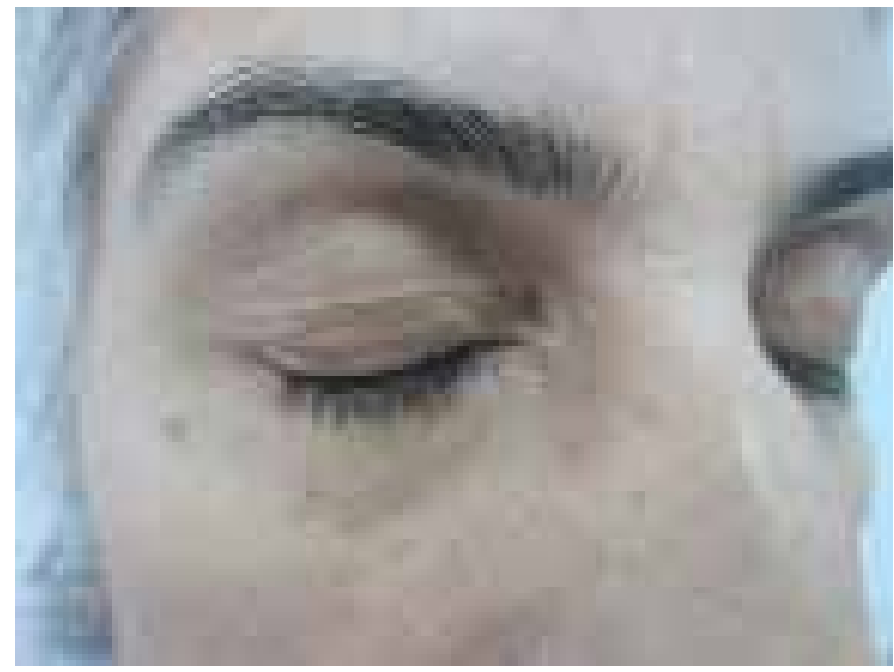

Resim 1. Ksantelezma: Tedaviden önce (1A) ve 2 seans tedaviden sonra (1B)
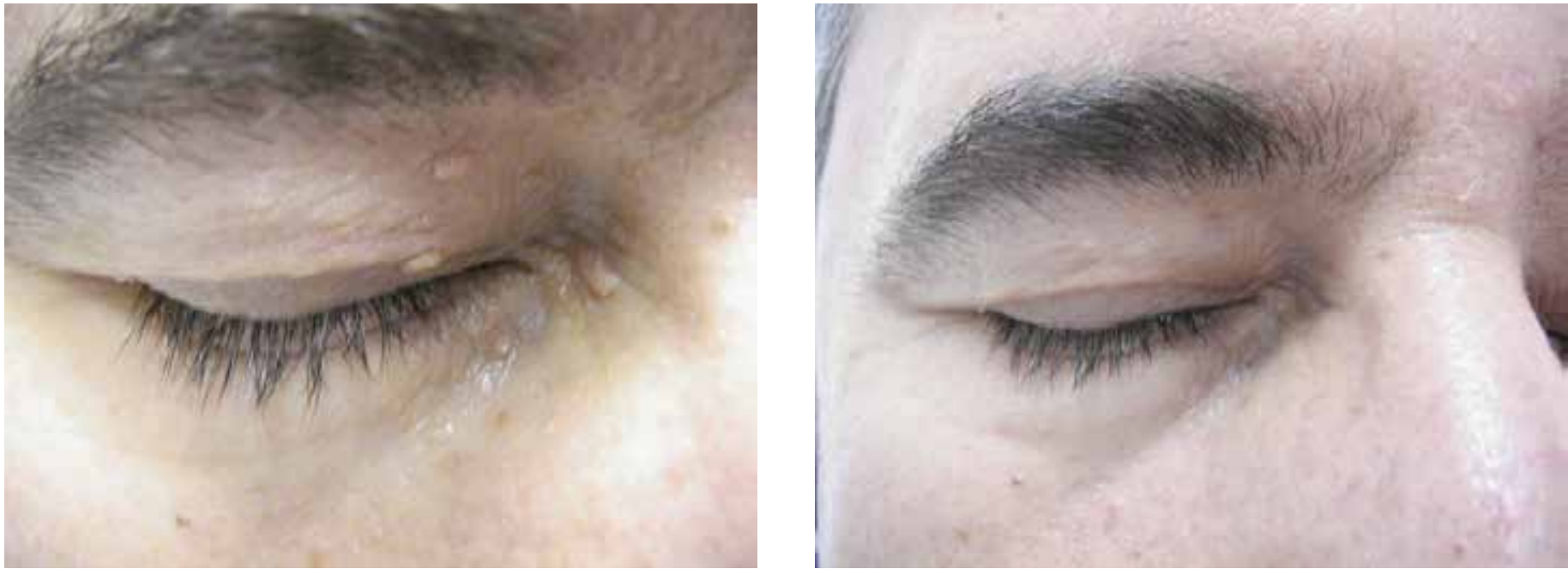

Resim 2. Siringoma: Tedaviden önce (2A) ve 2 seans tedaviden sonra (2B) 

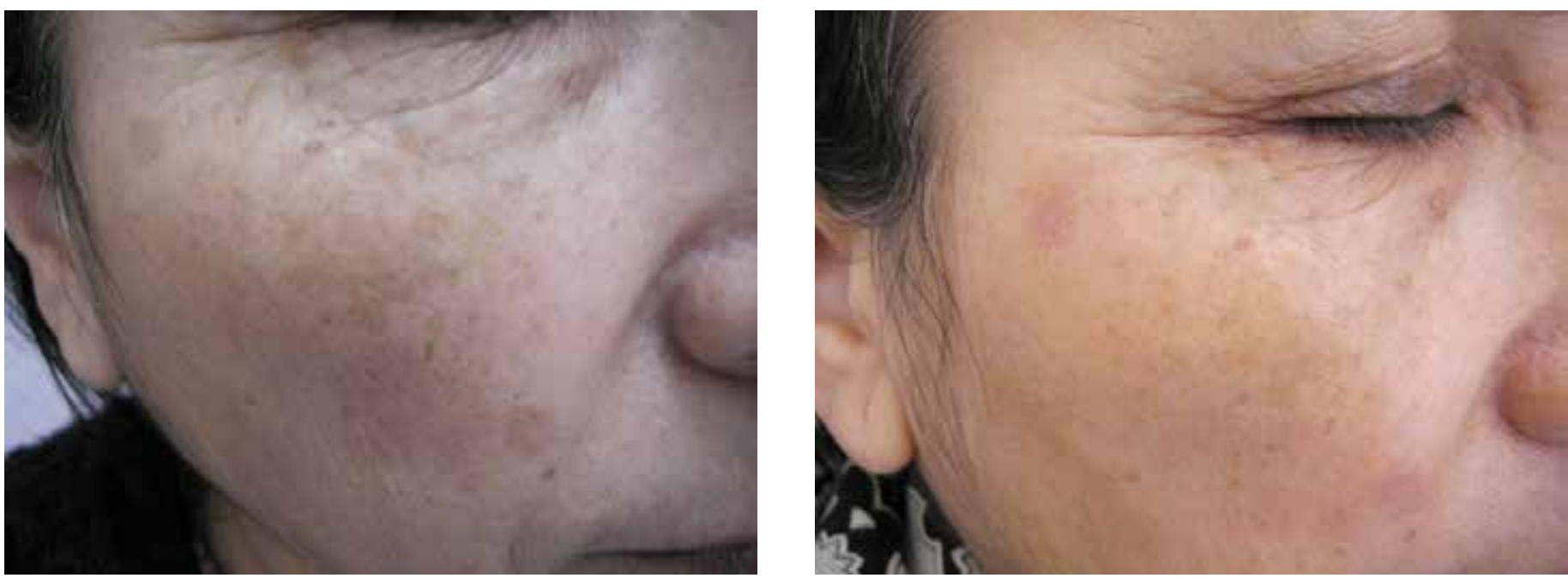

Resim 3. Solar lentigolu bir olgumuza ait tedavi öncesi ve sonrası fotoğrafları Resim 3A ve 3B'de gösterilmektedir
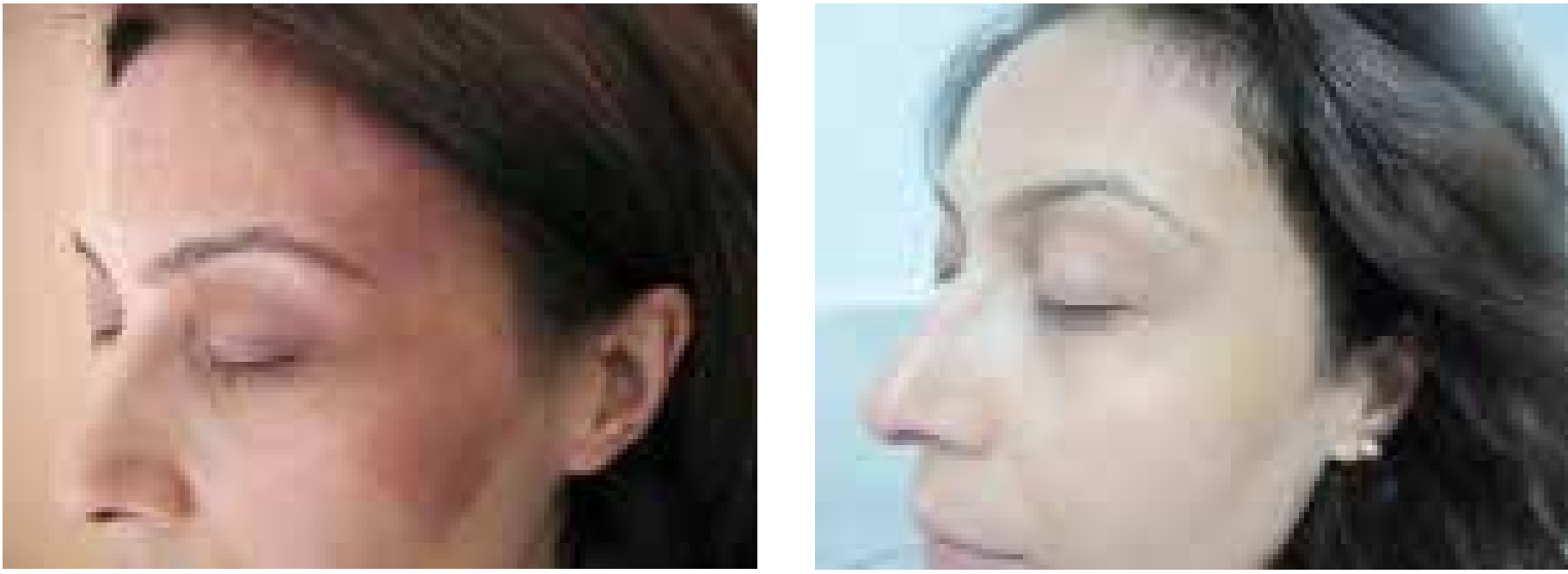

Resim 4. Ota Nevüs: Tedaviden önce (4A) ve 6 seans tedaviden sonra (4B)

yıl) idi. Lezyonların tedavisi için ortalama 1-4 seans lazer uygulaması yeterli olmuştur (akım şiddeti: 3-6 J/ $\mathrm{cm}^{2}$, frekansı: 3-7 $\mathrm{Hz}$, spot büyüklüğü: 3-5 mm, akım tipi: SP). Hastaların \%87,5'i tedaviye iyi yanıt vermiş olup, sonuç istatistiksel olarak anlamlı bulunmuştur $(p<0,05)$. Siringomalı bir olgumuza ait tedavi öncesi ve sonrası fotoğrafları Resim 3A ve 3B'de gösterilmektedir.

Epidermal nevüs nedeniyle toplam 11 hasta (5 erkek, 6 kadın) Er: YAG lazer ile tedavi edildi. Hastaların yaş ortalaması 25 (yaş aralığı 20-30 yıl) idi. Epidermal nevüslerin deriden kabarık verrüköz özellik göstermesinden dolayı tedavi için ortalama 3-6 seans lazer uygulamasına ihtiyaç duyulmuştur (akım şiddeti: 3-6 J/cm2, frekansı: 3-6 Hz, spot büyüklüğü: 3-5 mm, akım tipi: SP). Hastaların \%90,9'u tedaviye iyi yanıt vermiş olup, sonuç istatistiksel olarak anlamlı bulunmuştur $(p<0,05)$.

Seboreik keratoz nedeniyle toplam 9 hasta (5 erkek, 4 kadın) Er: YAG lazer ile tedavi edildi. Hastaların yaş ortalaması 38,8 (yaş aralığı 29-47 yıl) idi. Seboreik keratoz lezyonlarının tedavisi için ortalama 1-2 seans lazer uygulaması yeterli olmuştur (akım şiddeti: 4-6 J/ $\mathrm{cm}^{2}$, frekansı: 4-6 Hz, spot büyüklüğü: 2-5 mm, akım tipi: SP). Hastaların tamamı tedaviye iyi yanıt vermiş olup, sonuç istatistiksel olarak anlamlı bulunmuştur $(p<0,05)$.

Ota nevüs nedeniyle toplam 5 hasta (2 erkek, 3 kadın) Er: YAG lazer ile tedavi edildi. Hastaların yaş ortalaması 32,6 (yaş aralığı 20-54 yıl) idi. Lezyonların derin yerleşim göstermesinden dolayı tedavi için ortalama 3-7 seans lazer uygulamasına ihtiyaç duyulmuştur (akım şiddeti: 4-6 J/cm², frekansı: 3-8 Hz, spot büyüklüğü: 4-5 mm, akım tipi: SP). Hastaların \%20'si tedaviye iyi yanıt vermiş olup, sonuç istatistiksel olarak anlamsız bulunmuştur $(p>0,05)$. Ota nevüslü bir olgumuza ait tedavi öncesi ve sonrası fotoğrafları Resim $4 A$ ve $4 B^{\prime}$ de gösterilmektedir.

CALM nedeniyle toplam 3 hasta (2 erkek, 1 kadın) Er: YAG lazer ile tedavi edildi. Hastaların yaş ortalaması 21,5 (yaş aralığı 21-22 yıl) idi. CALM tedavisi için ortalama 2-3 seans lazer uygulaması yeterli olmuştur (akım şiddeti: 4-5 J/cm², frekansı: 4-6 Hz, spot büyüklüğü: 4-5 mm, akım tipi: SP). Hastaların \%66,6'sı tedaviye iyi yanıt vermiş olup, sonuç istatistiksel olarak anlamlı bulunmuştur $(p<0,05)$. 
Tablo 1. Hastaların demografik özellikleri, lezyon tipleri ve tedavi parametreleri

\begin{tabular}{|c|c|c|c|c|c|c|c|c|c|}
\hline Özellikler & $\begin{array}{l}\text { Ksantelezma } \\
(n=21)\end{array}$ & $\begin{array}{l}\text { Siringoma } \\
(n=17)\end{array}$ & $\begin{array}{l}\text { Solar } \\
\text { Lentigo } \\
(n=16)\end{array}$ & $\begin{array}{l}\text { Epidermal } \\
\text { Nevüs } \\
(n=11)\end{array}$ & $\begin{array}{l}\text { Seboreik } \\
\text { Keratoz } \\
(n=9)\end{array}$ & $\begin{array}{l}\text { Ota } \\
\text { Nevüs } \\
(n=5)\end{array}$ & $\begin{array}{l}\text { CALM } \\
(n=3)\end{array}$ & $\begin{array}{l}\text { Diğer } \\
\text { Lezyonlar } \\
(n=21)\end{array}$ & $\begin{array}{l}\text { Toplam } \\
(n=103)\end{array}$ \\
\hline \multicolumn{10}{|l|}{ Cinsiyet, n (\%) } \\
\hline Erkek & $5(\% 23,8)$ & $11(\% 64,7)$ & $5(\% 31,2)$ & $5(\% 45,4)$ & $5(\% 55,5)$ & $2(\% 40)$ & $2(\% 66,6)$ & $12(\% 57,1)$ & $\begin{array}{l}47 \\
(\% 45,6)\end{array}$ \\
\hline Kadın & $16(\% 76,2)$ & $6(\% 35,3)$ & $11(\% 68,8)$ & $6(54,6)$ & $4(\% 44,5)$ & $3(\% 60)$ & $1(\% 33,4)$ & $9(\% 42,8)$ & $\begin{array}{l}56 \\
(\% 54,4)\end{array}$ \\
\hline $\begin{array}{l}\text { Yaş, ortalama } \\
\text { (dağılım) }\end{array}$ & $38,5(21-51)$ & $\begin{array}{l}26,2 \\
(21-31)\end{array}$ & $\begin{array}{l}42,5 \\
(21-74)\end{array}$ & $25(20-30)$ & $\begin{array}{l}38,8 \\
(29-47)\end{array}$ & $\begin{array}{l}32,6 \\
(20-54)\end{array}$ & $\begin{array}{l}21,3 \\
(21-22)\end{array}$ & $\begin{array}{l}38,5 \\
(15-68)\end{array}$ & $\begin{array}{l}35,6 \\
(15-74)\end{array}$ \\
\hline \multicolumn{10}{|c|}{ Fitzpatrick deri tipi, n (\%) } \\
\hline ॥ & $8(\% 38)$ & $6(\% 35,3)$ & $10(\% 62,5)$ & $5(\% 45,4)$ & $3(\% 33,3)$ & $2(\% 40)$ & $2(\% 66,6)$ & $11(\% 52,3)$ & $\begin{array}{l}47 \\
(\% 45,6)\end{array}$ \\
\hline III & $13(\% 62)$ & $11(\% 64,7)$ & $6(\% 37,5)$ & $6(\% 54,6)$ & $6(\% 66,7)$ & $3(\% 60)$ & $1(\% 33,4)$ & $10(\% 47,7)$ & $\begin{array}{l}56 \\
(\% 54,4) \\
\end{array}$ \\
\hline \multicolumn{10}{|l|}{ Yerleşim yeri, n (\%) } \\
\hline Yüz ve boyun & $21(\% 100)$ & $17(\% 100)$ & $14(\% 87,5)$ & $9(\% 81,8)$ & $9(\% 100)$ & $\begin{array}{c}5 \\
(\% 100) \\
\end{array}$ & $2(\% 66,6)$ & $19(\% 90,4)$ & $\begin{array}{l}96 \\
(\% 93,2) \\
\end{array}$ \\
\hline Diğer & $0(\% 0)$ & $0(\% 0)$ & $2(\% 12,5)$ & $2(\% 18,2)$ & $0(\% 0)$ & $0(\% 0)$ & $1(\% 33,4)$ & $2(\% 9,6)$ & $7(\% 6,8)$ \\
\hline \multicolumn{10}{|l|}{ Boyut, $\mathrm{cm}^{2}, \mathrm{n}(\%)$} \\
\hline$<20$ & $21(\% 100)$ & $17(\% 100)$ & $16(\% 100)$ & $9(\% 81,8)$ & $9(\% 100)$ & $1(\% 20)$ & $3(\% 100)$ & $15(\% 71,4)$ & $\begin{array}{l}91 \\
(\% 88,3)\end{array}$ \\
\hline $20-40$ & $0(\% 0)$ & $0(\% 0)$ & $0(\% 0)$ & $0(\% 0)$ & $0(\% 0)$ & $1(\% 20)$ & $0(\% 0)$ & $3(\% 14,3)$ & $4(\% 3,9)$ \\
\hline $40-60$ & $0(\% 0)$ & $0(\% 0)$ & $0(\% 0)$ & $2(18,2)$ & $0(\% 0)$ & $1(\% 20)$ & $0(\% 0)$ & $1(\% 4,8)$ & $4(\% 3,9)$ \\
\hline$>60$ & $0(\% 0)$ & $0(\% 0)$ & $0(\% 0)$ & $0(\% 0)$ & $0(\% 0)$ & $2(\% 40)$ & $0(\% 0)$ & $2(\% 9,5)$ & $4(\% 3,9)$ \\
\hline Akım, J/cm² & $5-7$ & $5-7$ & $3-6$ & $3-6$ & $4-6$ & $4-6$ & $4-5$ & $4-6$ & $3-7$ \\
\hline Frekans, Hz & $5-6$ & $5-6$ & $3-7$ & $3-6$ & $4-6$ & $4-8$ & $4-6$ & $4-6$ & $3-6$ \\
\hline Spot büyüklüğü, mm & $3-5$ & $3-5$ & $3-5$ & $3-5$ & $2-6$ & $4-5$ & $4-5$ & $3-5$ & $2-6$ \\
\hline Atım tipi & SP & SP & SP & $S P$ & SP & SP & $\mathrm{SP}$ & SP & SP \\
\hline $\begin{array}{l}\text { Seans sayısı, } \\
\text { ortalama }\end{array}$ & $1-2$ & $2-3$ & $1-4$ & $3-6$ & $1-2$ & $3-8$ & $2-3$ & $3-5$ & $1-8$ \\
\hline
\end{tabular}

Tablo 2. Lezyon tiplerine göre tedavi yanıtları

\begin{tabular}{|c|c|c|c|c|c|c|c|c|c|}
\hline $\begin{array}{l}\text { Klinik } \\
\text { Yanit }\end{array}$ & $\begin{array}{l}\text { Ksantelezma } \\
(n=21)\end{array}$ & $\begin{array}{l}\text { Siringoma } \\
(n=17)\end{array}$ & $\begin{array}{l}\text { Solar } \\
\text { Lentigo } \\
(n=16)\end{array}$ & $\begin{array}{l}\text { Epidermal } \\
\text { Nevüs } \\
(n=11)\end{array}$ & $\begin{array}{l}\text { Seboreik } \\
\text { Keratoz } \\
(n=9)\end{array}$ & $\begin{array}{l}\text { Ota } \\
\text { Nevüs } \\
(n=5)\end{array}$ & $\begin{array}{l}\text { CALM } \\
(n=3)\end{array}$ & $\begin{array}{l}\text { Diğer } \\
\text { Lezyonlar } \\
(n=21)\end{array}$ & $\begin{array}{l}\text { Toplam } \\
(n=103)\end{array}$ \\
\hline $0-25$ & $0(\% 0)$ & $0(\% 0)$ & $0(\% 0)$ & $0(\% 0)$ & $0(\% 0)$ & $2(\% 40)$ & $0(\% 0)$ & $3(\% 14,3)$ & $5(\% 4,9)$ \\
\hline $26-50$ & $0(\% 0)$ & $1(\% 5,9)$ & $2(\% 12,5)$ & $1(\% 9,1)$ & $0(\% 0)$ & $2(\% 40)$ & $1(\% 33,3)$ & $3(\% 14,3)$ & $10(\% 9,7)$ \\
\hline $51-75$ & $8(\% 38,1)$ & $2(\% 11,8)$ & $5(\% 31,2)$ & $2(\% 18,2)$ & $1(\% 11,1)$ & $1(\% 20)$ & $1(\% 33,3)$ & $7(\% 33,3)$ & $27(\% 26,2)$ \\
\hline $76-100$ & $13(\% 61,9)$ & $14(\% 82,3)$ & $9(\% 56,3)$ & $8(\% 72,7)$ & $8(\% 88,9)$ & $0(\% 0)$ & $1(\% 33,3)$ & $8(\% 38,1)$ & $61(\% 59,2)$ \\
\hline Toplam & 21 (\%100) & 17 (\%100) & $16(\% 100)$ & $11(\% 100)$ & $9(\% 100)$ & $5(\% 100)$ & $3(\% 100)$ & 21 (\%100) & 103 (\%100) \\
\hline
\end{tabular}

Bunların dışında postinflamatuvar hiperpigmentasyon ( $n=5)$, melazma $(n=4)$, aktinik keratoz $(n=4)$, melanositik nevüs $(n=3)$, nevüs sebaseus $(n=3)$, travmatik tatuaj $(n=1)$ ve yanık skarı $(n=1)$ nedeniyle toplam 21 hasta (12 erkek, 9 kadın) Er: YAG lazer ile tedavi edildi. Lezyonun tipine göre tedavi seansları farklılık göstermekle birlikte ortalama 3-5 seans lazer uygulanmıştır (akım şiddeti: 4-6 J/ $\mathrm{cm}^{2}$, frekansı: 4-6 Hz, spot büyüklüğü: 3-5 mm, akım tipi: SP). Hastaların \%85,4'ü tedaviye iyi yanıt vermiştir.

Tüm hasta grupları beraber değerlendirildiğinde hastaların $\% 59,2$ 'sinde belirgin düzelme, \%26,2'sinde orta derecede düzelme ve $\% 9,7$ 'sinde hafif düzelme saptanırken, $\% 4,9^{\prime}$ unda düzelme saptanmamıştır. Lezyon tiplerine göre tedavi yanıtları Tablo 2'de özetlenmiştir. Hastaların tedavi memnuniyeti üzerine doldurdukları anketler incelenmiş ve sonuçları Tablo 3'te özetlenmiştir. Hastaların \%43,7'si tedavi sonucunu çok iyi, \%35'i ise iyi bulduğunu belirtmiştir. Hastaların \%12,6'sı Er: YAG lazer ile uygulanan ablazyon tedavisinden fayda görmediğini ifade etmiştir. Tedaviden memnun kalmadığını belirten hastaların dosyaları incelendiğinde bu hastaların tedavi sonrası komplikasyon gelişen olgular olduğu gözlenmiştir.

Tedavi sonrası izlenen yan etkileri değerlendirdiğimizde hastaların 


\begin{tabular}{|c|c|c|c|c|c|c|c|c|}
\hline $\begin{array}{l}\text { Ksantelezma } \\
(n=21)\end{array}$ & $\begin{array}{l}\text { Siringoma } \\
(n=17)\end{array}$ & $\begin{array}{l}\text { Solar Lentigo } \\
(n=16)\end{array}$ & $\begin{array}{l}\text { Epidermal } \\
\text { Nevüs } \\
(n=11)\end{array}$ & $\begin{array}{l}\text { Seboreik } \\
\text { Keratoz } \\
(n=9)\end{array}$ & $\begin{array}{l}\text { Ota Nevüs } \\
(n=5)\end{array}$ & $\begin{array}{l}\text { CALM } \\
(n=3)\end{array}$ & $\begin{array}{l}\text { Diğer } \\
\text { Lezyonlar } \\
(\mathbf{n}=\mathbf{2 1})\end{array}$ & $\begin{array}{l}\text { Toplam } \\
(n=103)\end{array}$ \\
\hline $10(\% 47,6)$ & $3(\% 17,6)$ & $6(\% 37,5)$ & $3(\% 27,3)$ & $0(\% 0)$ & $3(\% 60)$ & $1(\% 33,3)$ & $10(\% 47,6)$ & $36(\% 35)$ \\
\hline $1(\% 4,8)$ & $1(\% 5,9)$ & $2(\% 12,5)$ & $1(\% 9,1)$ & $0(\% 0)$ & $0(\% 0)$ & $0(\% 0)$ & $4(\% 19)$ & $9(\% 8,7)$ \\
\hline $0(\% 0)$ & $0(\% 0)$ & $0(\% 0)$ & $1(\% 9,1)$ & $0(\% 0)$ & $0(\% 0)$ & $0(\% 0)$ & $1(\% 4,8)$ & $2(\% 1,9)$ \\
\hline $21(\% 100)$ & $17(\% 100)$ & $16(\% 100)$ & $11(\% 100)$ & $9(\% 100)$ & $5(\% 100)$ & $3(\% 100)$ & $21(\% 100)$ & $\begin{array}{l}103 \\
(\% 100)\end{array}$ \\
\hline
\end{tabular}

Tablo 4. Lezyon tiplerine göre gözlenen yan etkiler

\begin{tabular}{|c|c|c|c|c|c|c|c|c|c|}
\hline Yan Etkiler & $\begin{array}{l}\text { Ksantelezma } \\
(n=21)\end{array}$ & $\begin{array}{l}\text { Siringoma } \\
(n=17)\end{array}$ & $\begin{array}{l}\text { Solar } \\
\text { Lentigo } \\
(n=16)\end{array}$ & $\begin{array}{l}\text { Epidermal } \\
\text { Nevüs } \\
(n=11)\end{array}$ & $\begin{array}{l}\text { Seboreik } \\
\text { Keratoz } \\
(n=9)\end{array}$ & $\begin{array}{l}\text { Ota Nevüs } \\
(n=5)\end{array}$ & $\begin{array}{l}\text { CALM } \\
(n=3)\end{array}$ & $\begin{array}{l}\text { Diğer } \\
\text { Lezyonlar } \\
(n=21)\end{array}$ & $\begin{array}{l}\text { Toplam } \\
(n=103)\end{array}$ \\
\hline Hiperpigmentasyon & $0(\% 0)$ & $1(\% 5,9)$ & $1(\% 6,2)$ & $1(\% 9)$ & $0(\% 0)$ & $1(\% 20)$ & $0(\% 0)$ & $1(\% 4,8)$ & $5(\% 4,9)$ \\
\hline Hipopigmentasyon & $1(\% 4,8)$ & $0(\% 0)$ & $1(\% 6,2)$ & $0(\% 0)$ & $0(\% 0)$ & $0(\% 0)$ & $1(\% 33,3)$ & $1(\% 4,8)$ & $4(\% 3,9)$ \\
\hline Atrofik Skar & $1(\% 4,8)$ & $0(\% 0)$ & $0(\% 0)$ & $0(\% 0)$ & $0(\% 0)$ & $0(\% 0)$ & $0(\% 0)$ & $0(\% 0)$ & $1(\% 1)$ \\
\hline Hipertrofik Skar & $0(\% 0)$ & $0(\% 0)$ & $0(\% 0)$ & $1(\% 9)$ & $0(\% 0)$ & $0(\% 0)$ & $0(\% 0)$ & $1(\% 4,8)$ & $2(\% 1,9)$ \\
\hline Toplam & $2(\% 9,6)$ & $1(\% 5,9)$ & $2(\% 12,4)$ & $2(\% 18)$ & $0(\% 0)$ & $2(\% 40)$ & $2(\% 66,6)$ & $3(\% 14,4)$ & $14(\% 13,6)$ \\
\hline
\end{tabular}

çoğunda birkaç gün süren eritem, yanma, akıntı ve kabuklanma oluştuğu ve bir hafta içinde herhangi bir iz bırakmadan kaybolduğu görülmüştür. Bu etkilerin geçici olması ve hastalar üzerinde herhangi bir olumsuz etki oluşturmaması nedeniyle yan etki olarak değerlendirmeye alınmamıştır. Değerlendirmeye alınan yan etkileri incelediğimizde 4 hastada hiperpigmentasyon, 3 hastada hipopigmentasyon, 2 hastada hipertrofik skar ve 1 hastada kalıcı eritem geliştiği izlenmiştir. Lezyon tiplerine göre gözlenen yan etkiler Tablo 4'te özetlenmiştir. Ciddi morbidite oluşturan hipertrofik skarın, epidermal nevüs ve travmatik tatuaj nedeniyle tedavisinde yüksek enerji kullandığımız iki hastada geliştiği gözlenmiştir.

\section{Tartışma}

Epidermal ve dermal benin ve premalin deri lezyonlarının tedavisinde cerrahi, kriyoterapi, elektrokoterizasyon ve lazer gibi birçok tedavi yöntemi bulunmaktadır. Epidermal ve dermal benin deri lezyonlarının tedavisinde ablatif lazer sistemleri, 80'li yıllarda karbondioksit lazerlerin keşfiyle kullanıma girmiştir. Eski sistem lazerler, derin ablazyon nedeniyle skar riskine sahipti. Lazer sistemlerindeki gelişmelerle birlikte günümüzde, selektif fototermoliz özelliği ile su molekülünü kromofor olarak seçen kısa atım süresine sahip Er: YAG lazer sistemleri geliştirilmiştir. Er: YAG lazerler yüksek enerjiyi kısa sürede dokuya vermekte ve çevre dokuda termal hasar oluşturmaksızın hassas bir ablazyona neden olmaktadır ${ }^{1}$

Ksantelezma tedavisinde kullanılan ilk lazer sistemleri argon lazer ve dye lazer olmuştur. Ancak her iki lazer sistemi de düşük penetrasyon özellikleri nedeniyle derin yerleşim gösteren lezyonların tedavisinde yetersiz kalmaktadır. Ksantelezma tedavisinde günümüzde en çok kullanılan lazer sistemleri karbondioksit lazer ve Er: YAG lazerdir. Karbondioksit lazer ile yapılan çalışmalarda hastalarda kozmetik olarak kabul edilebilir düzelme sağlanırken, rekürrens oranının \%13 olduğu bildirilmiştir ${ }^{3}$. Ancak selektif fototermoliz özelliği olmayan bu lazer sistemlerinde oluşan termal hasar çevre dokulara zarar vermekte ve tedavi sonrasında eritem, süresinin uzamasına, yara iyileşmesinin gecikmesine, postinflamatuvar hiper/hipopigmentasyon oluşmasına neden olabilmektedir. Bu yan etkilerinden dolayı günümüzde daha güvenli bir tedavi seçeneği olan Er: YAG lazer sistemleri ön plana çıkmıştır. Kliniğimizde Er: YAG lazer ile tedavi ettiğimiz 21 ksantelezmalı hastanın tamamında \%50'den fazla düzelme sağladık ancak bir hastada tedavi memnuniyeti beklenenin altında olmuştur. Bizim çalışmamıza benzer şekilde, Borelli ve Kaudewitz yaptıkları çalışmada 33 ksantelezma lezyonuna Er: YAG lazer uygulamışlar ve tedavi sonunda lezyonlarda belirgin düzelme ve yüksek hasta memnuniyeti sağlamışlardı ${ }^{4}$ Tedavi sonrasında rekürrens ve yan etki oluşumu her iki çalışmada da saptanmamıştır. Bu sonuçlar ışı̆̆ında ksantelezma tedavisinde Er: YAG lazer, etkili ve güvenilir bir tedavi seçeneği olarak değerlendirilebilir.

Siringoma tedavisinde çeşitli tedavi yöntemleri kullanılmasına karşın günümüzde ablatif lazer sistemleri en sık kullanılan tedavi yöntemi olmuştur. Kliniğimizde siringoma nedeniyle Er: YAG lazer tedavisi uyguladığımız 17 hastanın 16'sında \%50'den fazla düzelme sağladık ve sadece bir hastada hiperpigmentasyon oluşumu izlendi. ïleri dönemde bu yan etkinin gerilediği görüldü. Siringomanın lazerle tedavisinde yapılan çalışmaların genellikle karbondioksit lazer ile yapıldığı, Er: YAG lazer ile sadece bir çalışmanın yapıldığını gördük. Bu çalışmada, Riedel ve ark.'ı siringoma nedeniyle Er: YAG lazer tedavisi uyguladıkları tüm hastalarda düzelme sağladıklarını belirtmişlerdir ${ }^{5}$. Karbondioksit lazer 
ile yapılan çalışmada ise Cho ve ark.'ı 35 hastaya ablazyon uygulamışlar ve hastaların \%42,9'unda \%50'den fazla düzelme sağlamışlardır ${ }^{6}$. Her iki lazer sisteminde izlenen bu farkın en önemli nedeni Cho ve ark.'nın fraksiyonel karbondioksit lazer sistemini kullanmalarıdır. Tüm bu sonuçlar ışı̆̆ında siringoma tedavisinde Er: YAG lazer sisteminin etkili ve güvenilir bir tedavi olduğu kanaatindeyiz.

Solar lentigo lezyonlarında lazer tedavileri melanin pigmentinin 351-1064 nm arasında geniş bir absorbsiyon spektrumuna sahip olmasından dolayı farklı sistemleri kapsamaktadır ${ }^{7}$. Pulsed dye lazer, frekansı katlanmış Nd: YAG lazer, Q-anahtarlı aleksandrite lazer, Q-anahtarlı ruby lazer ve Q-anahtarlı Nd: YAG lazer; pigment spesifik özelliklerinden dolayı sıklıkla tedavide kullanılmaktadır. Bunların dışında yüzeyel yerleşim göstermelerinden dolayı ablatif özellikleri ön planda olan karbondioksit lazer ve Er: YAG lazer sistemleri günümüzde tercih edilen diğer bir lazer tedavisi seçeneğidir. Solar lentigo lezyonlarının tedavisinde Er: YAG lazer sıklıkla kullanılmasına karşın literatürde bildirilen çalışmalar olgu serileri şeklinde olmasından dolayı kanıt düzeyi düşüktür ${ }^{8}$ Khatri; yaptığı bir çalışmada kutanöz lezyonların tedavisinde Er: YAG lazer ile ablazyon tedavisini değerlendirmiş ve tedavi ettiği 34 solar lentigo lezyonunun sadece 3 'ünde rekürens izlemiştir. Ayrıca tedavi sonrası yan etki izlenmediğini bildirmiştir ${ }^{9}$. Biz de kliniğimizde solar lentigo nedeniyle tedavi ettiğimiz 16 hastanın 14'ünde \%50'nin üzerinde düzelme sağladık. Khatri'nin tek bir seansta klinik yanıt elde etmesinde en önemli etmen $10 \mathrm{~J} / \mathrm{cm}^{2}$ gibi yüksek dozda ablazyon uygulamasıdır. Biz ise olası yan etkileri en aza indirmek için $6 \mathrm{~J} / \mathrm{cm}^{2}$ dozunda tedavi uyguladık ve tama yakın yanıtı çoklu seansların sonunda elde ettik. Ancak düşük dozda tedavi uygulamamıza karşın tedavi sonrası bir olguda hiperpigmentasyon, bir olguda ise hipopigmentasyon izledik. Bu yan etkilerin izlenmesinde en önemli etmen hastaların Tip III deri tipine sahip olması ve tedavi sonrasında lezyonların güneşten korunmasında yeterli önlemlerin alınmaması olduğunu düşünmekteyiz. Bu sonuçlar doğrultusunda Er: YAG lazer sistemleri solar lentigo tedavisinde etkili bir yöntem olarak öne çıkmaktadır ancak diğer lazer sistemleri arasındaki etkinlik farkını ortaya koymak için karşılaştırmalı çalışmalara intiyaç vardır.

Epidermal nevüs tedavisinde en sık kullanılan lazerler karbondioksit lazer ve Er: YAG lazer sistemleridir. Devamlı atımlı karbondioksit lazer verrüköz epidermal nevüs tedavisinde etkili olmasına karşın yüksek skar oluşum riski kullanımını ciddi ölçüde kısıtlamaktadır ${ }^{10}$. Epidermal nevüs tedavisinde Er: YAG lazerin kullanımı ile ilgili sadece olgu serileri bulunmaktadır. Pearson ve Harland yaptıkları çalışmada, epdermal nevüslü 6 hastayı Er: YAG lazer ile tedavi etmişler ve tüm hastalarda kozmetik olarak mükemmel sonuçlar elde etmişlerdir ${ }^{11}$. Biz de kliniğimizde epidermal nevüsü olan 11 hastayı Er: YAG lazer ile tedavi ettik ve hastaların 10'unda \%50'den fazla düzelme sağladık. Sadece bir hastada tedavi sonrası hipertrofik skar oluşumu izlendi. Tedavi ettiğimiz olgularda Pearson ve Harland'ın yaptıkları çalışmaya oranla daha düşük bir yanıt izlememizin en önemli nedeni tedavi ettiğimiz lezyonların geniş alanı kaplayan verrüköz epidermal nevüsler olmasıdır. Elde ettiğimiz sonuçlar doğrultusunda epidermal nevüs olgularında Er: YAG lazer tedavisinin, önceki tedavi modaliteleri ile karşılaştırdığımızda daha etkili ve güvenilir olduğu kanaatindeyiz.

Seboreik keratoz lezyonlarında lazer tedavisi uzun süredir kullanılmasına karşın etkinliği üzerine sadece olgu serileri bulunmaktadır. Khatri yaptığı çalışmada seboreik keratozu olan 79 hastayı Er: YAG lazer ile tedavi etmiş ve hastaların tamamında tam bir kür sağlamıştır ${ }^{9}$. Biz de kliniğimizde 9 olguda tedavi uyguladık ve hastaların tamamında belirgin bir düzelme sağladık ve herhangi bir yan etki izlemedik. Er: YAG lazer, seboreik keratoz lezyonların tedavisinde etkili ve güvenilir bir seçenek olarak karşımıza çıkmaktadır.

Ota nevüs tedavisinde lazer sistemlerinin keşfiyle birlikte ilk olarak ablatif lazerler ve sonrasında pigment spesifik Q-anahtarlı lazerler kullanılmaya başlanmıştır. Ablatif lazerlerin etkinliği pigment spesifik lazerlere oranla daha düşük olmasından dolayı literatürlerde karbondioksit lazer ve Er: YAG lazerin ota nevüs tedavisinde kullanımı hakkında ayrıntılı bilgi bulunmamakta, elde edilen veriler klinik tecrübelere dayanmaktadır. Kliniğimizde ota nevüs nedeniyle Er: YAG lazer tedavisi uyguladığımız 5 hastanın sadece birinde \%50'den fazla düzelme sağladık ve bir hastada yan etki olarak kalıcı eritem gelişti. Pigment spesifik lazer ile yapılan çalışmalarla karşılaştırdığımızda, Geronemus; Ota nevüsü olan 15 hastayı Q-anahtarlı ruby lazer ile tedavi etmiş ve hastaların tamamında \%50'den fazla düzelme sağlamıştır ${ }^{12}$. Kar ve Gupta, daha koyu tene sahip Hint toplumunda yaptıkları çalışmada Ota nevüsü olan 50 hastayı Q-anahtarlı Nd: YAG lazer ile tedavi etmişler ve hastaların \%30'unda \%50'den fazla düzelme sağlamışlardır ${ }^{13}$. Yapılan çalışmaları değerlendirdiğimizde Ota nevüs lezyonlarının tedavisinde Er: YAG lazer sistemlerinin diğer pigment spesifik lazerlere oranla daha düşük etkinliğe sahip olduğunu izledik.

CALM tedavisinde başlıca kullanılan lazer sistemleri pigment spesifik özelliğe sahip Q-anahtarlı lazerlerdir. Bu lazer sistemlerinin etkinliğini göstermek için Kim ve ark. tedaviye dirençli CALM lezyonu olan bir hastayı Q-anahtarlı Nd: YAG lazer ile tedavi etmişler ve toplam 10 seans tedavi sonrasında lezyonun belirgin bir şekilde düzeldiğini bildirmişlerdir ${ }^{14}$. Er: YAG lazer sistemlerinin CALM lezyonlarında etkinliği konusunda randomize kontrollü çalışmalar bulunmamakla birlikte Alora ve ark.'ı bildirdikleri bir çalışmada Q-anahtarlı lazer tedavisine yanıt vermeyen bir olguda Er: YAG lazer tedavisinin etkili olduğunu ifade etmişlerdir ${ }^{15}$. Kliniğimizde CALM lezyonları nedeniyle tedavi ettiğimiz 3 hastadan 2'sinde \%50'den fazla düzelme sağladık ve hastaların hiçbirinde yan etki gözlemedik. Ayrıca hastaların tamamı tedaviden memnun kalmıştır. Er: YAG lazer sistemleri CALM lezyonlarının tedavisinde Q-anahtarlı lazerler kadar etkili olmamasına karşın, tedaviye dirençli olgularda etkili bir tedavi seçeneği olabileceği kanaatindeyiz.

Bunların dışında kliniğimizde nevüs sebaseus, postinflamatuvar hiperpigmentasyon, sebase hiperplazi, yanık skarı, travmatik tatuaj ve aktinik keratoz lezyonlarının tedavisinde de Er: YAG lazer uyguladık. Toplam 21 hastanın 15'inde \%50'den fazla düzelme sağladık. Sadece bir hasta tedaviden memnun kalmadığını belirtmiştir. Yine bu hasta grubunda yan etki olarak bir hastada hiperpigmentasyon, bir hastada hipopigmentasyon ve bir hastada da hipertrofik skar oluşumu izledik. Travmatik tatuaj tedavisinde Er: YAG lazer uyguladığımı hastada hipertrofik skar oluşumu izlenmiş olup, hasta tedaviden memnun kalmadığını belirtmiştir.

\section{Sonuç}

Er: YAG lazer tedavisinin epidermal ve dermal yerleşim gösteren deri lezyonlarında etkili bir tedavi seçeneği olabileceğini düşünmekteyiz. Özellikle epidermal yerleşimin ön planda olduğu ksantelezma, siringoma, solar lentigo, epidermal nevüs, seboreik keratoz, nevüs 
sebaseus ve aktinik keratoz lezyonlarının tedavisinde diğer sistemlerden daha etkili ve güvenilir bir tedavi seçeneği olduğunu düşünüyoruz. Ancak Ota nevüs gibi derin yerleşimli pigmente lezyonlarda ve genodermatozlara bağı pigmente lezyonlarda, daha düşük etkinliğe sahip olduğunu değerlendirdik. Postinflamatuvar hiperpigmentasyon tedavisinde, tedavi sonrası kısmi düzelme izlenmesine karşın bu tip lezyonlarda tekrarlama riski bulunması Er: YAG lazer tedavisinin etkinliğini kısıtlamaktadır. Er: YAG lazer ile herhangi bir deri lezyonunun tedavisinde, uygulayan hekimin tecrübesinin, uygun enerji parametreleri kullanmasının tedavi başarısını arttırması yanında yan etkileri azaltmasında en önemli faktör olduğunu düşünüyoruz. Er: YAG lazerin deri lezyonlarında etkinliğini tam olarak ortaya koymak için iyi dizayn edilmiş, hasta sayısının daha fazla olduğu çalışmalara ihtiyaç duyulmaktadır.

\section{Kaynaklar}

1. Riggs $K$, Keller M, Humphreys TR: Ablative laser resurfacing: high-energy pulsed carbon dioxide and erbium:yttrium-aluminum-garnet. Clin Dermatol 2007;25:462-73.

2. Kutlubay Z, Gokdemir G: Treatment of atrophic facial acne scars with the Er:YAG laser: a Turkish experience. J Cosmet Laser Ther 2010;12:65-72.

3. Raulin C, Schoenermark MP, Werner S, Greve B: Xanthelasma palpebrarum: treatment with the ultrapulsed CO2 laser. Lasers Surg Med 1999;24:122-7.
4. Borelli C, Kaudewitz P: Xanthelasma palpebrarum: treatment with the erbium:YAG laser. Lasers Surg Med 2001;29:260-4.

5. Riedel F, Windberger J, Stein E, Hormann K: Treatment of peri-ocular skin lesions with the erbium:YAG laser. Ophthalmologe 1998;95:771-5.

6. Cho SB, Kim HJ, Noh S, Lee SJ, Kim YK, Lee JH: Treatment of syringoma using an ablative 10,600-nm carbon dioxide fractional laser: a prospective analysis of 35 patients. Dermatol Surg 2011;37:433-8.

7. Ortonne JP, Pandya AG, Lui H, Hexsel D: Treatment of solar lentigines. J Am Acad Dermatol 2006;54:262-71.

8. Dmovsek-Olup B, Vedlin B: Use of Er:YAG laser for benign skin disorders. Lasers Surg Med 1997;21:13-9.

9. Khatri KA:Ablation of cutaneous lesions using an erbium:YAG laser. J Cosmet Laser Ther 2003;5:150-3.

10. Hohenleutner $\mathrm{U}$, Landthaler M: Laser therapy of verrucous epidermal naevi. Clin Exp Dermatol 1993;18:124-7.

11. Pearson IC, Harland CC: Epidermal naevi treated with pulsed erbium:YAG laser. Clin Exp Dermatol 2004;29:494-6.

12. Geronemus RG: Q-switched ruby laser therapy of nevus of Ota. Arch Dermatol 1992;128:1618-22.

13. Kar HK, Gupta L: 1064 nm Q switched Nd: YAG laser treatment of nevus of Ota: an Indian open label prospective study of 50 patients. Indian J Dermatol Venereol Leprol 2011;77:565-70.

14. Kim JS, Kim MJ, Cho SB: Treatment of segmental cafe-au-lait macules using 1064-nm Q-switched Nd:YAG laser with low pulse energy. Clin Exp Dermatol 2009;34:e223-4

15. Alora MB, Arndt KA: Treatment of a cafe-au-lait macule with the erbium:YAG laser. J Am Acad Dermatol 2001;45:566-8. 